\title{
Valor Nutritivo e Desempenho de Coelhos em Crescimento Alimentados com Rações Contendo Milho Extrusado 1
}

\section{Antonio Claudio Furlan², Renilda Terezinha Monteiro ${ }^{3}$, Claudio Scapinello ${ }^{2}$, Ivan Moreira ${ }^{2}$, Alice Eiko Murakami ${ }^{2}$, Luciana Kazue Otutumi ${ }^{3}$, Maurício Luiz da Rosa Santolin 4}

RESUMO - Dois experimentos foram conduzidos com o objetivo de avaliar a utilização do milho, processado ou não por extrusão, na alimentação de coelhos em crescimento. No experimento 1, foram utilizados 21 coelhos da raça Nova Zelândia Branco, 12 machos e 9 fêmeas, com 55 dias de idade, em um ensaio de digestibilidade, para determinar o valor nutritivo do milho, processado ou não por extrusão. Os coelhos foram distribuídos em um delineamento inteiramente casualizado com três tratamentos e sete repetições, sendo uma ração referência e duas rações testes. Na elaboração das rações testes, o alimento avaliado (milho, processado ou não por extrusão) substituiu a ração referência em percentuais de $30 \%$ com base na matéria natural. Os coeficientes de digestibilidade da matéria seca, matéria orgânica, proteína bruta, amido e energia bruta foram, respectivamente, de 81,$39 ; 88,24 ; 87,08 ; 98,63$ e 90,24\% para o milho não processado de 86,$46 ; 96,96 ; 94,11 ; 98,91$ e $97,54 \%$ para o milho extrusado. Os teores de matéria seca digestível, matéria orgânica digestível, proteína digestível, amido digestível, e energia digestível, com base na matéria seca, foram, respectivamente, de 71,16; 87,27; 7,78; 60,09 e 3997 kcal/kg para o milho não processado e de 75,$6 ; 95,9 ; 8,41 ; 60,26 \%$ e $4320 \mathrm{kcal} / \mathrm{kg}$ para o milho extrusado. No Experimento 2, foram utilizados 80 coelhos da raça Nova Zelândia Branco, metade de cada sexo, no período de 35 a 75 dias de idade, com o objetivo de avaliar o desempenho de coelhos em crescimento, alimentados com rações contendo diferentes níveis de substituição do milho pelo milho extrusado. Os animais foram distribuídos em um delineamento inteiramente casualizado com quatro tratamentos e vinte repetições. Os tratamentos consistiram de quatro rações isoenergéticas, sendo uma ração testemunha à base de milho comum não processado e outras três rações onde o milho comum foi substituído em níveis de 33, 66 e 100\%, pelo milho extrusado. A inclusão de níveis crescentes de milho extrusado nas rações não afetou o ganho de peso médio diário, a conversão alimentar, o peso e rendimento de carcaça, porém, reduziu linearmente o consumo de ração médio diário. O uso do milho extrusado ou não, fica na dependência do preço de mercado e disponibilidade.

Palavras-chave: composição química, desempenho, digestibilidade, valor energético

\section{Nutritive Value and Performance of Growing Rabbits Fed Rations Containing Extruded Corn}

\begin{abstract}
Two experiments were carried out, with the aim of evaluating the use of corn processed or not by extrusion, in the feeding of growing rabbits. In the experiment 1, 21 White New Zealand rabbits, 12 males and 9 females, with 55 days of age, were used on digestibility assay, with the aim of determining the nutritional value of corn, extruded or not. The rabbits were distributed in a completely randomized design with three treatments and seven replications, with one reference and four test diets. In the elaboration of test diets, the evaluated feeds (corn processed or not on extrusion) replaced the reference diet in 30\% in natural matter. The digestibility coefficients of dry matter, organic matter, crude protein, starch and gross energy were respectively, 81.39, 88.24, 87.08, 98.63 and 90.24\% for the corn not processed and $86.46,96.96,94.11,98.91$ and $97.54 \%$ for the extruded corn. The digestible dry matter, digestible organic matter, digestible protein, digestible starch and digestible energy, based on dry matter were respectively, 71.16, 87.27, 7.78, 60.09\% and $3997 \mathrm{kcal} / \mathrm{kg}$ for the corn not processed and of 75.6, 95.9, 8.41, 60.26\% and $4320 \mathrm{kcal} / \mathrm{kg}$ for the extruded corn. In the experiment 2, 80 White New Zealand rabbits were used, half of each sex, in the period from 35 to 75 days of age, with the aim of evaluating the performance of growing rabbits fed with rations containing different replacement levels of corn by the extruded corn. The rabbits were allocated in a completely randomized design with four treatments and twenty replications. The treatments consisted of four isoenergetic ration, one as reference ration, with base on common corn not processed and the other three rations where the common corn was replaced, in levels of 33, 66 and $100 \%$, by the extruded corn. The inclusion of increasing levels of extruded corn in the rations did not affect the daily average weight gain, feed:gain ratio, weight and carcass yield, however it reduced linearly daily average feed intake. It can be concluded that corn extruded or not can replace totally the corn in rations. The use of extruded corn extruded or not in rations depends on market price and availability.
\end{abstract}

Key Words: chemical composition, performance, digestibility, energy value

\footnotetext{
${ }^{1}$ Trabalho parcialmente financiado pelo CNPq.

${ }^{2}$ Professor do DZO-UEM - Maringá, PR. E.mail: acfurlan@uem.br

3 Pós-graduando do PPZ-DZO-UEM.

${ }^{4}$ Bolsista de Iniciação Científica do CNPq-UEM.
} 


\section{Introdução}

O conhecimento da composição química e valor energético dos alimentos usados nas rações de coelhos é primordial para a formulação de dietas econômicas que atendam as exigências nutricionais dos coelhos.

Poucos trabalhos têm sido conduzidos, com o objetivo de descrever o valor nutricional dos alimentos para coelhos. O milho e o farelo de soja vêm sendo avaliados por pesquisadores (Fekete \& Gippert, 1986; Scapinello, 1993), contudo, alimentos alternativos necessitam de estudos de tal forma a serem utilizados também nas formulações de rações.

O milho é a principal fonte energética, não só nas dietas de coelhos, mas nas dietas dos animais em geral. O componente químico responsável pelo conteúdo energético do milho é o amido, que representa por volta de 70 a $80 \%$ de seu peso seco. Compreende uma mistura de amilose (22-28\%) e amilopectina (78$72 \%$ ), formando um complexo altamente organizado.

Scapinello et al. (1995) determinaram para o milho coeficientes de digestibilidade de $86,29 \%$, para a matéria seca, $84,69 \%$, para a proteína bruta e $87,24 \%$, para a energia bruta.

Por outro lado, estudos têm demonstrado que a utilização de alimentos com elevado conteúdo de amido, durante a fase de desmame e pós-desmame, é considerada como uma das causas possíveis de distúrbios digestivos em coelhos, cujo sistema enzimático não está ainda bem desenvolvido (Blas et al., 1994; Maertens, 1995), além do amido do milho se encontrar em um complexo altamente organizado de amilose-amilopectina, na forma granular, que não são prontamente acessíveis à ação da amilase no processo de digestão.

De acordo com Gidenne (1998), citado por Blas \& Gidenne (1998), o processamento por extrusão do milho levou a uma redução no nível de amido ileal de coelhos em crescimento, independente da idade (28 ou 49 dias). O processamento por extrusão provoca transformações físicas benéficas nos grânulos de amido, provocando uma mudança estrutural, favorecendo, conseqüentemente, a ação enzimática.

Quando submetido ao calor úmido, o grão de amido absorve água, expande-se, exuda parte da amilose, ocorrendo rupturas das ligações secundárias do hidrogênio que prendem a cadeia do polímero, tornando-se mais susceptível à degradação enzimática. Portanto, o processamento de alimentos com alto teor de amido por meio de calor úmido, além de alterar as características físicas, tem melhorado o valor nutritivo, visto que, durante este processamento, ocorre gelatinização do amido e mudanças conformacionais nas moléculas protéicas, melhorando a digestibilidade, principalmente do amido e proteína, tornando-os mais susceptíveis à degradação enzimática (Lawrence, 1985; Rooney \& Pflugfeuder, 1986).

Maertens \& Luzi (1995), verificaram que a extrusão de dietas ricas em amido melhorou a solubilidade in vitro do amido, mas não teve efeito em reduzir as perdas fecais de amido em coelhos de cinco a sete semanas de idade, alimentados com dietas ricas em amido. Mendez et al. (1998), concluíram que o processo de extrusão envolve um alto custo de energia, aumentando o custo do produto.

Existem poucas pesquisas desenvolvidas em coelhos sobre a utilização de alimentos processados por extrusão. Desta forma, o presente trabalho teve como objetivos determinar, por meio de ensaio de digestibilidade, o valor nutritivo do milho, processado ou não por extrusão, avaliar o desempenho e características de carcaça de coelhos em crescimento alimentados com rações contendo níveis crescentes de milho processado por extrusão e, verificar a viabilidade econômica de sua inclusão, na alimentação de coelhos em crescimento.

\section{Material e Métodos}

Dois experimentos foram conduzidos no Setor de Cunicultura da Fazenda Experimental de Iguatemi, da Universidade Estadual de Maringá.

No ensaio de digestibilidade foram utilizados 21 coelhos da raça Nova Zelândia Branco, 12 machos e 9 fêmeas, com idade média inicial de 55 dias, distribuídos em um delineamento inteiramente casualizado, com três tratamentos e sete repetições.

Os animais foram alojados individualmente em gaiolas de metabolismo, providas de bebedouros automáticos, comedouros semi-automáticos e dispositivos de coleta, em separado, de fezes e urina, instaladas em galpão de alvenaria, pé direito de três metros, com cobertura de telha de barro.

O período experimental teve duração de dez dias, dos quais seis foram para adaptação dos animais às instalações e dietas e, quatro dias, para a coleta de fezes.

O milho (processado ou não por extrusão) substituiu uma ração referência (Tabela 1) em percentuais de $30 \%$ na matéria natural, constituindo, desta forma, três rações experimentais, que foram peletizadas a seco. 
Tabela 1 - Composição percentual e química da ração referência

Table 1 - Chemical and percentual composition of reference ration

\begin{tabular}{|c|c|}
\hline $\begin{array}{l}\text { Ingredientes } \\
\text { Ingredients }\end{array}$ & $\%$ \\
\hline Milho, moído & 18,53 \\
\hline Corn & \\
\hline Farelo de soja & 12,03 \\
\hline Soybean meal & \\
\hline Farelo de trigo & 20,00 \\
\hline Wheat meal & \\
\hline $\begin{array}{l}\text { Feno de alfafa } \\
\text { Alfalfa hay }\end{array}$ & 25,00 \\
\hline Feno de aveia & 20,28 \\
\hline Oat hay & \\
\hline Sal comum & 0,50 \\
\hline Salt & \\
\hline Calcário & 0,39 \\
\hline Limestone & \\
\hline Fosfato bicálcico & 0,60 \\
\hline Dicalcium phosphate & \\
\hline Suplemento vitamínico e mineral & 0,50 \\
\hline $\begin{array}{l}\text { Vitamin and mineral supplement } \\
\text { DL-Metionina }\end{array}$ & 0,08 \\
\hline DL-methionine & \\
\hline Óleo vegetal & 2,09 \\
\hline Vegetable oil & \\
\hline Total & 100,00 \\
\hline Composição calculada ${ }^{1}$ & \\
\hline Calculated composition & \\
\hline Proteína bruta $(\%)$ & 17,23 \\
\hline Crude protein (\%) & \\
\hline Fibra bruta $(\%)$ & 14,50 \\
\hline Crude fiber (\%) & \\
\hline $\mathrm{ED}(\mathrm{kcal} / \mathrm{kg})$ & 2.450 \\
\hline$D E(\mathrm{kcal} / \mathrm{kg})$ & \\
\hline Cálcio (\%) & 0,80 \\
\hline Calcium (\%) & \\
\hline Fósforo (\%) & 0,50 \\
\hline Phosphorus (\%) & \\
\hline Met+Cis $(\%)$ & 0,60 \\
\hline Met + Cis $(\%)$ & \\
\hline Lisina $(\%)$ & 0,80 \\
\hline Lysine (\%) & \\
\hline
\end{tabular}

${ }^{1}$ Com base nos valores de composição químicas das matériasprimas das rações (Based on the values of chemical composition of the raw materials of the rations).

2 Suplemento vitamínico - mineral, composição por kg do produto: Vit A, 300.000 UI; Vit D, 50.000 UI; Vit E, 4.000 mg; Vit K3, 100 $\mathrm{mg}$; Vit B1, $200 \mathrm{mg}$; Vit B2, $300 \mathrm{mg}$, Vit B6, $100 \mathrm{mg}$; Vit B12, 1.000 mcg; Ac. Nicotínico, $1.500 \mathrm{mg}$; Ac. Pantotênico, $1.000 \mathrm{mg}$; Colina, 35.000 mg; Ferro, 4.000 mg; Cobre, 600 mg; Cobalto, 100 $\mathrm{mg}$; Manganês, $4.300 \mathrm{mg}$; Zinco, $6.000 \mathrm{mg}$; lodo, $32 \mathrm{mg}$; Selênio, $8 \mathrm{mg}$; Metianina, $60.000 \mathrm{mg}$; Promotor de Crescimento, $1.500 \mathrm{mg}$; Coccidiostático, $12.500 \mathrm{mg}$; Antioxidante, $10.000 \mathrm{mg}$ (Vitaminmineral premix (Nuvital) composition per Kg: Vit A, 300.000 UI; Vit D, 50.000 UI: Vit E, $4.000 \mathrm{mg}$; Vit K3, $100 \mathrm{mg}$; Vit B1, $200 \mathrm{mg}$; Vit B2, $300 \mathrm{mg}$, Vit B6, $100 \mathrm{mg}$; Vit B12, $1.000 \mathrm{mcg}$; Nicotinic ac, $1.500 \mathrm{mg}$; Panthotenic ac, $1.000 \mathrm{mg}$; Choline, $35.000 \mathrm{mg}$; Iron, $4.000 \mathrm{mg}$; Copper, $600 \mathrm{mg}$; Cobalt, 100 mg; Manganese, $4.300 \mathrm{mg}$, Zinc, $6.000 \mathrm{mg}$; lodine, $32 \mathrm{mg}$; Selenium, $8 \mathrm{mg}$; Methionine, $60.000 \mathrm{mg}$; Growing prom., $1.500 \mathrm{mg}$; Coccidiostat, $12.500 \mathrm{mg}$; Sinox. $10.000 \mathrm{mg}$ ).

R. Bras. Zootec., v.32, n.5, p.1157-1165, 2003
O milho processado foi extrusado em uma extrusora IMBRA 120 da empresa IMBRAMAC, com a capacidade para $120 \mathrm{~kg} /$ hora, com temperatura no interior do canhão de $115^{\circ} \mathrm{C}$ e pressão de $1 \mathrm{a} 2 \mathrm{~atm}$.

Para determinação dos teores de matéria seca digestível, de matéria orgânica digestível, de proteína digestível, do amido digestível e de energia digestível, foi utilizada a equação de Matterson et al. (1965).

Os animais receberam água e ração à vontade durante todo o experimento, sendo as rações fornecidas uma vez ao dia, durante o período experimental.

As fezes coletadas, diariamente, pela manhã, foram acondicionadas em congelador a $-10^{\circ} \mathrm{C}$. No final do período de coleta, foram colocadas em estufa ventilada a $55^{\circ} \mathrm{C}$, por um período de 72 horas, para pré-secagem. Posteriormente, as amostras foram expostas ao ar, para que houvesse equilíbrio com a temperatura e umidade ambiente, sendo, então, pesadas, moídas e homogeneizadas, retirando-se amostras do material pré-seco para análises.

As análises químicas dos ingredientes, das rações e das fezes foram realizadas de acordo com os métodos descritos por Silva (1990) e as análises de energia, em um calorímetro PARR, modelo 1281.

No experimento de desempenho foram utilizados 80 coelhos da raça Nova Zelândia Branco, metade de cada sexo, no período de 35 a 75 dias de idade, alojados em gaiolas de arame galvanizado, providas de bebedouro automático e comedouro semi-automático de chapa galvanizada, localizadas em galpão de alvenaria, com cobertura de telha francesa, pé-direito de 3,0 metros, piso em alvenaria, paredes laterais de $50 \mathrm{~cm}$ em alvenaria e o restante em tela e cortina de plástico para controle de ventos.

A temperatura média registrada no período experimental, de maio a junho de 2001 , foi de $18^{\circ} \mathrm{C}$, sendo que a máxima registrada foi de $26^{\circ} \mathrm{C}$ e a mínima de $9^{\circ} \mathrm{C}$.

Os animais foram distribuídos em um delineamento experimental inteiramente casualizado, com quatro tratamentos e vinte repetições, com um animal por unidade experimental. Os tratamentos consistiram de uma ração testemunha à base de milho comum não processado (Tabela 2) e outras três rações onde o milho comum não processado foi substituído em níveis de 33, 66 e $100 \%$, pelo milho extrusado.

Os valores energéticos do milho, extrusado ou não, determinados no experimento de digestibilidade, foram utilizados para formular as rações experimentais, que foram isoenergéticas, isoaminoacídicas para 
Tabela 2 - Composição percentual e química das rações experimentais Table 2 - Chemical and percentual composition of experimental rations

\begin{tabular}{lc}
\hline Ingredientes & Ração testemunha \\
Ingredients & Control ration
\end{tabular}

Níveis de substituição do milho não processado pelo milho extrusado (\%)

\begin{tabular}{|c|c|c|c|c|}
\hline & & Replacem & corn not $p$ & xtruded cor \\
\hline & & 33 & 66 & 100 \\
\hline Milho comum & 26,00 & 17,33 & 8,67 & - \\
\hline Corn & & & & \\
\hline Milho extrusado & - & 7,81 & 15,62 & 23,43 \\
\hline Extruded corn & & & & \\
\hline Farelo de soja & 10,40 & 10,00 & 9,60 & 9,20 \\
\hline Soybean meal & & & & \\
\hline Farelo de trigo & 19,49 & 21,00 & 22,51 & 24,00 \\
\hline Wheat meal & & & & \\
\hline Feno de alfafa & 20,00 & 20,00 & 20,00 & 20,00 \\
\hline Alfalfa hay & & & & \\
\hline Feno de aveia & 20,00 & 20,00 & 20,00 & 20,00 \\
\hline Oats hay & & & & \\
\hline SalComum & 0,50 & 0,50 & 0,50 & 0,50 \\
\hline Common salt & & & & \\
\hline Calcário & 0,56 & 0,61 & 0,63 & 0,65 \\
\hline Limestone & & & & \\
\hline $\mathrm{L}-\mathrm{Lis} \mathrm{HCl}$ & 0,09 & 0,10 & 0,10 & 0,11 \\
\hline$L$-Lis $H C L$ & & & & \\
\hline Fosfato bicálcico & 0,65 & 0,58 & 0,53 & 0,50 \\
\hline Dicalcium phosphate & & & & \\
\hline Suplemento vitamínico e mineral ${ }^{2}$ & 0,50 & 0,50 & 0,50 & 0,50 \\
\hline Vitamin and mineral supplement & & & & \\
\hline $\mathrm{DL}$-metionina & 0,10 & 0,10 & 0,10 & 0,10 \\
\hline DL-methionine & & & & \\
\hline Óleo Vegetal & 1,70 & 1,46 & 1,23 & 1,00 \\
\hline Vegetable oil & & & & \\
\hline Antioxidante & 0,01 & 0,01 & 0,01 & 0,01 \\
\hline Antioxidant & & & & \\
\hline Total & 100 & 100 & 100 & 100 \\
\hline Composição calculada ${ }^{1}$ & & & & \\
\hline Calculated composition ${ }^{l}$ & & & & \\
\hline Proteína bruta(\%) & 16,09 & 16,10 & 16,09 & 16,10 \\
\hline Crude Protein (\%) & & & & \\
\hline Fibra bruta & 13,20 & 13,29 & 13,38 & 13,47 \\
\hline Crude fiber (\%) & & & & \\
\hline ED kcal / kg & 2544 & 2544 & 2544 & 2544 \\
\hline DE kcal kg & & & & \\
\hline Cálcio(\%) & 0,80 & 0,80 & 0,80 & 0,80 \\
\hline Calcium & & & & \\
\hline Fósforo(\%) & 0,50 & 0,50 & 0,50 & 0,50 \\
\hline Phosphorus & & & & \\
\hline Met $+\operatorname{Cist}(\%)$ & 0,60 & 0,60 & 0,60 & 0,60 \\
\hline Met + Cist (\%) & & & & \\
\hline $\operatorname{Lisina}(\%)$ & 0,80 & 0,80 & 0,80 & 0,80 \\
\hline Lysine (\%) & & & & \\
\hline
\end{tabular}

${ }^{1}$ Com base nos valores de composição químicas das matérias-primas das rações (Based on the values of chemical composition of the raw materials of the rations).

2 Suplemento Vitamínico - mineral, composição por kg do produto: Vit A, 300.000 UI; Vit D, 50.000 UI; Vit E, 4.000 mg; Vit K3, 100 mg; Vit B1, 200 mg; Vit B2, 300 mg, Vit B6, 100 mg; Vit B12, 1.000 mcg; Ac. Nicotínico, 1.500 mg; Ac. Pantotênico, 1.000 mg; Colina, 35.000 mg; Ferro, 4.000 mg; Cobre, 600 mg; Cobalto, 100 mg; Manganês, 4.300 mg; Zinco, 6.000 mg; lodo, 32 mg; Selênio, 8 mg; Metianina, $60.000 \mathrm{mg}$; Promotor de Crescimento, $1.500 \mathrm{mg}$; Coccidiostático, $12.500 \mathrm{mg}$; Antioxidante, $10.000 \mathrm{mg}$ (Vitamin-mineral premix (Nuvital) composition per Kg: Vit A, $300.000 \mathrm{Ul}$; Vit D, $50.000 \mathrm{UI}$; Vit E, $4.000 \mathrm{mg}$; Vit K3, $100 \mathrm{mg}$; Vit B1, 200 mg; Vit B2, $300 \mathrm{mg}$, Vit B6, $100 \mathrm{mg}$; Vit B12, 1.000 mcg; Nicotinic ac, 1.500 mg; Panthotenic ac, 1.000 mg; Choline, 35.000 mg; Iron, 4.000 mg; Copper, 600 mg; Cobalt, 100 mg; Manganese, 4.300 mg, Zinc, $6.000 \mathrm{mg}$; lodine, $32 \mathrm{mg}$; Selenium, $8 \mathrm{mg}$; Methionine, $60.000 \mathrm{mg}$; Growing prom., $1.500 \mathrm{mg}$; Coccidiostat, $12.500 \mathrm{mg}$; Sinox. $10.000 \mathrm{mg}$ ). 
metionina+cistina e lisina, isocálcicas e isofosfóricas. As rações foram formuladas de acordo com as recomendações para coelhos em crescimento, de De Blas \& Mateos (1998).

Após a mistura, as rações foram peletizadas a seco e o fornecimento das mesmas e de água foi à vontade. As rações fornecidas e as sobras também foram pesadas a cada pesagem dos animais.

Os coelhos foram pesados no início do experimento, com 35 dias de idade e, no final do experimento, aos 75 dias. O abate dos animais e a avaliação das carcaças, no final do experimento, foram realizados conforme descrição feita por Scapinello (1993).

Os preços dos ingredientes utilizados na elaboração dos custos das rações foram coletados na região de Maringá/PR, no mês de novembro de 2001: milho, $\mathrm{R} \$ 0,16 / \mathrm{kg}$; milho extrusado, R \$ 0,17; farelo de soja, $\mathrm{R} \$ 0,45 / \mathrm{kg}$; farelo de trigo, $\mathrm{R} \$ 0,14 / \mathrm{kg}$; feno de alfafa, $\mathrm{R} \$ 0,27 / \mathrm{kg}$; feno de aveia, R $\$ 0,18 / \mathrm{kg}$; sal comum, R\$ $0,15 / \mathrm{kg}$; calcário, $\mathrm{R} \$ 0,15 / \mathrm{kg}$; lisina, $\mathrm{R} \$ 0,50 / \mathrm{kg}$; fosfato bicálcico, R\$ 0,74/kg; suplemento vitamínico e mine$\mathrm{ral}, \mathrm{R} \$ 5,64 / \mathrm{kg}$; óleo vegetal, $\mathrm{R} \$ 1,32 / \mathrm{kg} ; \mathrm{BHT}$, $\mathrm{R} \$ 6,0 / \mathrm{kg}$ e DL- metionina, R\$ $10,18 / \mathrm{kg}$.

Para verificar a viabilidade econômica da substituição do milho comum pelo milho extrusado nas rações, determinou-se, inicialmente, o custo da ração por quilograma de peso vivo ganho $\left(\mathrm{Y}_{\mathrm{i}}\right)$, segundo Bellaver et al. (1985).

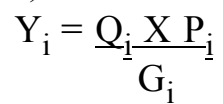

em que: $Y_{i}=$ custo da ração por quilograma de peso vivo ganho no i-ésimo tratamento; $\mathrm{P}_{\mathrm{i}}=$ preço por quilograma da ração utilizada no i-ésimo tratamento; $\mathrm{Q}_{\mathrm{i}}=$ quantidade de ração consumida no i-ésimo tratamento e $\mathrm{G}_{\mathrm{i}}=$ ganho de peso do i-ésimo tratamento.

Em seguida, foram calculados o Índice de Eficiência Econômica (IEE) e o Índice de Custo (IC), proposto por Barbosa et al. (1992).

$$
\mathrm{IEE}=\frac{\mathrm{MCei}}{\mathrm{CTei}} \times 100 \quad \text { e } \quad \text { IC }=\frac{\text { CTei }}{\text { MCei }} \times 100
$$

em que: $\mathrm{MCei}=$ menor custo da ração por quilograma ganho observado entre tratamentos; CTei = custo do tratamento i considerado.

As observações foram analisadas, de acordo com o modelo estatístico:

$$
\mathrm{Y}_{\mathrm{ijk}}=\mathrm{u}+\mathrm{N}_{\mathrm{i}}+\mathrm{S}_{\mathrm{j}}+\mathrm{N}_{\mathrm{i}} \mathrm{S}_{\mathrm{j}}+\mathrm{e}_{\mathrm{ijk}}
$$

em que: $Y_{i j k}=$ valor observado das variáveis estudadas relativas a cada indivíduo $\mathrm{k}$, do sexo $\mathrm{j}$, recebendo ração com nível de substituição do alimento $\mathrm{i}$; $\mathrm{u}=$ média geral da característica; $\mathrm{N}_{\mathrm{i}}=$ efeito do nível de substituição do alimento $\underline{i} ; S_{j}=$ efeito do sexo $\mathrm{j}$; $\mathrm{N}_{\mathrm{i}} \mathrm{S}_{\mathrm{j}}=$ efeito da interação nível de substituição $\mathrm{x}$ sexo; $e_{i j k}=$ erro aleatório associado a cada observação $\mathrm{Y}_{\mathrm{ijk}}$.

Os graus de liberdade referentes aos níveis de substituição, excluindo a ração testemunha, foram desdobrados em polinômios.

Para comparação dos resultados obtidos entre a ração referência com cada um dos níveis de substituição do alimento processado, foi utilizado o teste de Dunnett a $5 \%$.

\section{Resultados e Discussão}

A composição química do milho em matéria seca e cálcio, com base na matéria seca, está próxima àquela apresentada por Cheeke (1995), Scapinello et al. (1995) e Rostagno et al. (2000), entretanto, os níveis de proteína bruta e fósforo foram inferiores aos citados por estes autores (Tabela 3 ).

Os coeficientes de digestibilidade da matéria seca e do amido das rações referência e teste (Tabela 4) não diferiram entre si, enquanto, os coeficientes de digestibilidade da matéria orgânica (MO), da proteína bruta (PB) e energia bruta (EB) da ração teste, contendo milho extrusado (RME) foram superiores àqueles obtidos para a ração referência (RR) e ração com milho comum não processado (RM).

Esses maiores coeficientes em relação à $R R$ demonstram, primeiramente, o efeito positivo da inclusão destes alimentos à RR, ou seja, o processamento por extrusão trouxe benefícios à ração teste contendo milho extrusado (RME).

Os coeficientes de digestibilidade da MS e PB do milho extrusado ou não (Tabela 5) estão próximos aos obtidos para o milho por Scapinello et al. (1995), entretanto, o CD da EB apresenta grande superioridade. Os coeficientes de digestibilidade da PB determinado por Fekete \& Gippert (1986) para o milho foram inferiores.

Os coeficientes de digestibilidade da $\mathrm{MO}$ e da EB do milho extrusado foram maiores $(\mathrm{P}<0,05)$ que os obtidos para o milho não processado.

Verifica-se, portanto que o processamento por extrusão foi efetivo para o milho, melhorando os coeficientes de digestibilidade da $\mathrm{MO}$ e da EB.

A melhoria no CD da EB poderia ser explicado, 
Tabela 3 - Composição em matéria seca (MS), matéria orgânica (MO), energia bruta (EB), proteína bruta (PB), amido $(\mathrm{AM})$, cálcio $(\mathrm{Ca})$ e fósforo $(\mathrm{P})$ do milho ( base matéria seca) ${ }^{1}$

Table 3 - Dry matter (DM) in composition, organic matter (MO), gross energy (GE), crude protein (CP), starch(S), calcium (Ca) and phosphorum $(P)$ of corn (dry matter basis) ${ }^{1}$

\begin{tabular}{lccccccc}
\hline Alimento & MS (\%) & MO $(\%)$ & EB $(\mathrm{kcal} / \mathrm{kg})$ & PB $(\%)$ & AM $(\%)$ & Ca $(\%)$ & P $(\%)$ \\
Feed & $D M(\%)$ & $O M(\%)$ & GE $(\mathrm{kcal} / \mathrm{kg})$ & $\mathrm{CP}(\%)$ & $S(\%)$ & $C a(\%)$ & $P(\%)$ \\
\hline Milho & 87,44 & 98,91 & 4429 & 8,94 & 60,93 & 0,03 & 0,22
\end{tabular}

Corn

${ }^{1}$ Análises realizadas no Laboratório de Nutrição Animal no Departamento de Zootecnia da UEM.

${ }^{1}$ Analyses were performed at the Animal Nutrition Laboratory of Animal Science Departament of UEM.

em parte, em função da maior disponibilidade do amido nos processos de digestão dos alimentos processados, contudo, tal fato não ocorreu, visto que os coeficientes de digestibilidade do amido não diferiram $(\mathrm{P}>0,05)$ entre os alimentos avaliados. De acordo com Rooney \& Pflugfeulder (1986), a digestibilidade do amido depende de vários fatores, uma vez que os grânulos de amido não são todos semelhantes, diferindo em sua aparência, tamanho e propriedades, de acordo com a espécie vegetal. Esses autores afirmam ainda que o amido proveniente de cereais é mais facilmente digerido que amido oriundo de legumes, no entanto, existem diferenças entre cereais, em relação à textura do endosperma e relação amilose/amilopectina, sendo a digestibilidade do amido inversamente proporcional ao seu conteúdo de amilose, que no caso do milho, se encontra ao redor de $25 \%$.

O grão de amido, quando submetido ao processo de extrusão, absorve água, expande-se, exuda da parte amilose, ocorrendo ruptura das ligações secun-

Tabela 4 - Coeficiente de digestibilidade da matéria seca (MS), da matéria orgânica (MO), da proteína bruta (PB), do amido (AM) e da energia bruta (EB) da ração referência $(R R)$ e das rações testes contendo milho não processado (RM) e milho extrusado (RME)

Table 4 - Digestibility coefficients of dry matter (DM), organic matter (OM), crude protein (CP), starch (S) and gross energy of reference ration $(R R)$, containing corn not processed (CR) and extruded corn (ECR)

\begin{tabular}{lccccc}
\hline Ração & $\mathrm{MS}(\%)$ & $\mathrm{MO}(\%)$ & $\mathrm{PB}(\%)$ & $\mathrm{AM}(\%)$ & $\mathrm{EB}(\%)$ \\
Ration & $(D M) \%$ & $O M(\%)$ & $C P(\%)$ & $S(\%)$ & $G E(\%)$ \\
\hline $\mathrm{RR}$ & 79,84 & $60,21^{\mathrm{c}}$ & $76,18^{\mathrm{b}}$ & 98,11 & $60,34^{\mathrm{c}}$ \\
$\mathrm{RM}$ & 81,21 & $67,83^{\mathrm{b}}$ & $76,35^{\mathrm{b}}$ & 98,52 & $67,44^{\mathrm{b}}$ \\
$C R$ & & & & & \\
$\mathrm{RME}$ & 81,93 & $71,62^{\mathrm{a}}$ & $80,70^{\mathrm{a}}$ & 98,75 & $71,10^{\mathrm{a}}$ \\
$E C R$ & & & & &
\end{tabular}

Médias seguidas com letras diferentes na mesma coluna diferem $(P<0,05)$ pelo teste Tukey.

Means, in column, followed by different letters differ $(P<.05)$ by Tukey test. dárias de hidrogênio que prendem a cadeia do polímero, sendo esse processo chamado de gelatinização, o que leva a melhoras na digestibilidade.

Segundo Blas \& Gidenne (1998), a cutícula que reveste o grão de milho é também um dos fatores que faz com que haja redução na digestibilidade, visto que essa cutícula protege as moléculas das enzimas amilolíticas.

Maertens \& Luzi (1995) verificaram que a extrusão de dietas ricas em amido melhorou a solubilidade in vitro do amido da dieta, mas não teve efeito em reduzir as perdas fecais de amido em coelhos de cinco a sete semanas de idade alimentados com dietas ricas em amido.

Estudos recentes de Gidenne (1998), citado por Blas \& Gidenne (1998), mostram que a extrusão do milho levou à redução no nível de amido ileal de coelhos em crescimento, independentemente da idade (28 ou 49 dias).

A melhora obtida no CD da MO do milho extrusado pode ser um dos fatores positivos que contribuiu para o maior CD da EB do milho extrusado.

Tabela 5 - Coeficiente de digestibilidade da matéria seca (MS), da matéria orgânica (MO), da proteína bruta (PB), do amido (AM) e da energia bruta (EB) do milho (extrusado ou não)

Table 5 - Digestibility coefficients of dry matter (DM), organic matter (OM), crude protein (CP), starch (S) and gross energy (GE) of corn (extruded or not)

\begin{tabular}{lccccc}
\hline Alimento & $\mathrm{MS}(\%)$ & $\mathrm{MO}(\%)$ & $\mathrm{PB}(\%)$ & $\mathrm{AM}(\%)$ & $\mathrm{EB}(\%)$ \\
Feed & $(D M) \%$ & $O M(\%)$ & $C P(\%)$ & $S(\%)$ & $G E(\%)$ \\
\hline $\begin{array}{l}\text { Milho } \\
\begin{array}{l}\text { Corn } \\
\text { Milho }\end{array}\end{array}$ & 81,39 & $88,24^{\mathrm{b}}$ & 87,08 & 98,63 & $90,24^{\mathrm{b}}$ \\
$\begin{array}{l}\text { extrusado } \\
\text { Extruded corn }\end{array}$ & 86,46 & $96,96^{\mathrm{a}}$ & 94,11 & 98,91 & $97,54^{\mathrm{a}}$ \\
& & & & & \\
\end{tabular}

Médias seguidas com letras diferentes na mesma coluna diferem $(P<0,05)$ pelo teste $F$.

Means, in column, followed by different letters differ $(P<.05)$ by $F$ test.

R. Bras. Zootec., v.32, n.5, p.1157-1165, 2003 
O milho comum não processado e o milho extrusado apresentaram, respectivamente, conteúdo em energia digestível de 3495 e $3879 \mathrm{kcal} / \mathrm{kg} \mathrm{MN}$ ou de 3997 e $4320 \mathrm{kcal} / \mathrm{kg}$ MS (Tabela 6).

O teor de ED, com base na MS, superior em $8,1 \%$ para o milho extrusado, mostra o efeito benéfico do processamento por extrusão sobre este alimento. Este benefício, como mostrado anteriormente, não se deve, provavelmente, à gelatinização do amido durante a extrusão, visto que os coeficientes de digestibilidade do amido não foram diferentes entre o milho não processado e o milho extrusado. A melhora obtida na digestibilidade da MO contribuiu para a melhoria no valor energético do milho extrusado.

O teor de ED para o milho comum não processado, determinado neste experimento, é semelhante ao obtido por Fekete \& Gippert (1986), para coelhos em crescimento.

São escassos os trabalhos com a utilização de milho extrusado na alimentação de coelhos, porém, em pesquisas conduzidas com suínos, Moreira (1993) verificou que a extrusão do milho não melhorou a digestibilidade, que se manteve semelhante à do milho comum. Estes resultados diferem dos obtidos por Herkelmam et al. (1991), Skoch et al. (1983) e Noland et al. (1976), que encontraram melhoria na digestibilidade da energia do milho, milho + trigo e sorgo extrusados para suínos.

No experimento de desempenho, das características de desempenho e carcaça (Tabela 7), somente o consumo de ração foi afetado $(\mathrm{P}<0,05)$. A análise de regressão mostrou redução linear $(\mathrm{Y}=138,23$ -

Tabela 6 - Matéria seca digestível (MSD), matéria orgânica digestível (MOD), proteína digestível (PD), amido digestível $(A M D)$ e energia digestível (ED) do milho extrusado ou não, com base na matéria seca.

Table 6 - Digestible dry matter (DDM), digestible organic matter(DOM), digestible protein (DP), digestible starch (DS) and digestible energy (DE) of extruded or not corn, with dry matter basis

\begin{tabular}{lcccrc}
\hline $\begin{array}{l}\text { Nutrientes digestíveis } \\
\text { Digestible nutrients }\end{array}$ & $\begin{array}{c}\mathrm{MSD}(\%) \\
(\mathrm{DDM}) \%\end{array}$ & $\begin{array}{c}\mathrm{MOD}(\%) \\
O M D(\%)\end{array}$ & $\begin{array}{c}\mathrm{PD}(\%) \\
P D(\%)\end{array}$ & $\begin{array}{r}\mathrm{AMD}(\%) \\
D S\end{array}$ & $\begin{array}{r}\mathrm{ED}(\mathrm{kcal} / \mathrm{kg}) \\
D E(\mathrm{kcal} / \mathrm{kg})\end{array}$ \\
\hline $\begin{array}{l}\text { Milho } \\
\begin{array}{l}\text { Corn } \\
\text { Milho extrusado1 } \\
\text { Extruded corn }\end{array}\end{array}$ & 71,16 & 87,27 & 7,78 & 60,09 & 3997 \\
\hline
\end{tabular}

${ }^{1}$ MS do milho extrusado de $89,77 \%$.

${ }^{1} \mathrm{DM}$ of extruded corn of $89.77 \%$.

Tabela 7 - Ganho de peso médio diário (GPMD), consumo de ração médio diário (CRMD), conversão alimentar (CA), peso de carcaça (PC), rendimento de carcaça (RC) de coelhos em crescimento (35 - 75 dias) alimentados com rações com níveis crescentes de substituição do milho não processado pelo milho extrusado.

Table 7 - Daily average weight gain (DAWG), daily mean feed intake (DMFI), feed : gain ratio (F:G), carcass weight (CW), carcass yield (CY) of growing rabbits (35- 75 days) fed with ration of increasing replacement levels of the processed corn by extruded corn

\begin{tabular}{|c|c|c|c|c|c|}
\hline \multirow[b]{2}{*}{$\begin{array}{l}\text { Variável } \\
\text { Variable }\end{array}$} & \multicolumn{4}{|c|}{$\begin{array}{l}\text { Níveis de substituição do milho pelo milho extrusado (\%) } \\
\text { Replacement levels of the corn by extruded corn }\end{array}$} & \multirow[b]{2}{*}{$\mathrm{CV}^{1}$} \\
\hline & 0 & 33 & 66 & 100 & \\
\hline $\begin{array}{l}\text { GPMD }(\mathrm{g}) \\
D A W G(g)\end{array}$ & $38,94 \pm 1,38$ & $39,48 \pm 1,37$ & $39,93 \pm 1,27$ & $38,22 \pm 1,30$ & 13,36 \\
\hline $\begin{array}{l}\operatorname{CRMD}(\mathrm{g})^{2} \\
D M F I(g)\end{array}$ & $141,6 \pm 3,60$ & $137,7 \pm 3,59$ & $138,6 \pm 3,31$ & $128,1 \pm 3,40 *$ & 11,34 \\
\hline $\begin{array}{l}\mathrm{CA} \\
F G\end{array}$ & $3,53 \pm 0,56$ & $3,60 \pm 0,56$ & $3,45 \pm 0,51$ & $3,50 \pm 0,53$ & 6,73 \\
\hline $\begin{array}{l}\mathrm{PC}(\mathrm{g}) \\
C W(g)\end{array}$ & $1137 \pm 21,62$ & $1149 \pm 21,55$ & $1166 \pm 19,90$ & $1136 \pm 20,38$ & 8,41 \\
\hline $\begin{array}{l}\mathrm{RC}(\%) \\
C Y(g)\end{array}$ & $47,77 \pm 0,38$ & $49,09 \pm 0,38$ & $48,98 \pm 0,35$ & $49,44 \pm 0,36$ & 3,30 \\
\hline
\end{tabular}

${ }^{1}$ Coeficiente de variação (Coefficiente of variation).

2 Efeito linear $(P<0,05)$, $(Y=138,23-0,1532 X)$ (Linear effect $(P<.05),(Y=138.23-.1532 X)$.

* Difere da testemunha pelo teste de Dunnett $(P<0,05)$ (Differ from control by Dunnett test $[P<.05]$ ).

R. Bras. Zootec., v.32, n.5, p.1157-1165, 2003 
0,1532 X) do consumo diário médio com os níveis crescentes de substituição do milho pelo milho extrusado. Tal fato, provavelmente, esteja associado à formação de pó nas rações peletizadas à medida que o milho comum foi substituído por milho extrusado.

Aplicando o teste de Dunnett, no período de 35 a 75 dias de idade, apenas o consumo diário dos coelhos que receberam ração com $100 \%$ de milho extrusado foi menor $(\mathrm{P}<0,05)$ que aqueles animais que receberam a ração testemunha.

A ausência de diferenças entre os tratamentos aplicados para as características de desempenho e carcaça já era esperado, visto que as rações experimentais foram formuladas para serem isonutritivas.

Em pesquisas conduzidas com suínos, Moreira (1993) não verificou vantagens no desempenho de leitões de 21 a 42 dias alimentados com rações contendo milho extrusado.

Allee (1976), trabalhando com sorgo, não encontrou benefício da extrusão, sobre o desempenho de leitões de 8,1 kg de peso vivo. Essatara et al. (1976), citados por Lawrence (1985), também não observaram efeito da extrusão do milho sobre o desempenho de ratos em crescimento.

O custo da ração, por quilograma de peso vivo ganho, reduziu-se linearmente $(\mathrm{P}<0,05)(\mathrm{Y}=0,9372-$ $\left.0,0084 X ; R^{2}=0,68\right)$, com o aumento dos níveis de substituição do milho pelo milho extrusado (Tabela 8).

Comparando, pelo teste de Dunnett, o custo da ração (CR) por quilograma de peso vivo produzido da ração testemunha com cada um dos níveis de substituição do milho por milho extrusado, observaram-se diferenças somente com os níveis de 66 e $100 \%$ de substituição, obtendo nestes níveis os menores custos.

$\mathrm{O}$ índice de eficiência econômica e de custo foram numericamente melhores nas rações com $66 \mathrm{e}$ $100 \%$ de substituição do milho comum não processado por milho extrusado, mostrando ser viável economicamente a substituição total do milho comum por milho extrusado.

Tabela 8 - Custo da ração (CR), custo da ração por quilograma de peso vivo ganho de coelhos em crescimento (CRG), índice de eficiência econômica (IEE) e índice de custo (IC)

Table 8 - Cost of ration (CR), cost of ration per kilogram live weight gain of growing rabbits (GCR), economic efficiency index (EEI) and cost of index (Cl)

\begin{tabular}{|c|c|c|c|c|c|}
\hline \multirow[b]{2}{*}{$\begin{array}{l}\text { Variável } \\
\text { Variable }\end{array}$} & \multicolumn{4}{|c|}{$\begin{array}{l}\text { Níveis de substituição do milho pelo milho extrusado (\%) } \\
\text { Replacement levels of the corn by extruded corn }\end{array}$} & \multirow[b]{2}{*}{$\mathrm{CV}^{1}$} \\
\hline & 0 & 33 & 66 & 100 & \\
\hline $\begin{array}{l}\mathrm{CR}(\mathrm{R} \$ / \mathrm{kg}) \\
C R(R \$ / \mathrm{k} \sigma)\end{array}$ & 0,273 & 0,269 & 0,266 & 0,263 & - \\
\hline $\begin{array}{l}\text { CRG }(\mathrm{R} \$ / \mathrm{kg} \text { PV ganho })^{2} \\
G C R(R \$ / \mathrm{kg} L W G)^{2}\end{array}$ & 0,964 & 0,970 & $0,919^{*}$ & $0,921^{*}$ & 0,014 \\
\hline $\begin{array}{l}\text { IEE } \\
\text { EEI }\end{array}$ & 95,33 & 94,74 & 100 & 99,78 & - \\
\hline $\begin{array}{l}\mathrm{IC} \\
C I\end{array}$ & 104,89 & 105,65 & 100 & 100,21 & - \\
\hline
\end{tabular}

${ }^{1}$ Erro-padrão (Standard error).

${ }^{2}$ CRG; efeito linear $(P<0,05)\left(Y=0,9372-0,0084 X ; R^{2}=0,68\right)\left(C R ;\right.$ Linear effect $(P<.05)\left(Y=.9372-.0084 X ; R^{2}=.68\right)$.

* Difere da testemunha pelo teste Dunnett $(P<0,05)$ (Differ from control by Dunnett test $[P<.05])$.

\section{Conclusões}

O milho comum não processado pode ser substituído totalmente por milho extrusado nas rações de coelhos em crescimento sem prejudicar o desempenho. O seu uso em rações fica na dependência do preço de mercado e disponibilidade.

\section{Literatura Citada}

ALLEE, G. L. Effect of processing methods on nutritional value of milo for weaned pigs. Journal of Animal Science, v.43, p. $248,1976$.

BELLAVER, C.; FIALHO, E.T.; PROTAS, J.F.S. et al. Radícula de malte na alimentação de suínos em crescimento e terminação. Pesquisa Agropecuária Brasileira, v.20, n.8, p.969-974, 1985 . 
BARBOSA, C.; FIALHO, E.T.; PROTAS, J.F.S. et al. Radícula de malte na alimentação de suínos em crescimento e terminação. Pesquisa Agropecuária Brasileira, v.20, n.8, p.969-974, 1992.

BLAS, E.; CERVERA, C.; FERNADEZ CARMONA, J. Effect of two diets with varied starch and fiber levels on the performances of 4-7 weeks old rabbits.World Rabbit Science, v.2, n.4, p.117-121, 1994.

BLAS, E.; GIDENNE, T. Digestion of starch and sugars. In: DE BLAS, C.; WISEMAN, J. (Eds.). The nutrition of the rabbit. Cambridge: CABI Publishing, 1998. p.17-38.

CHEEKE, P.R. Alimentación y nutrición del conejo. Zaragoza: Acríbia, 1995. 429p.

DE BLAS, C.; MATEOS, G.G. Feed formulation. In: DE BLAS, C.; WISEMAN, J. (Eds.). The nutrition of the rabbit. Cambridge: CABI Publishing, 1998. p.241-253.

FEKETE, S.; GIPPERT, T. Digestibility and nutritive value of nineteen important feedstuffs for rabbits. Journal of Applied Rabbit Research, v.9, n.3, p.103-108, 1986.

HERKELMAN, K.L.; CROMWELL, G.L.; STAHLY, T.S. Effects of heating time and sodium metabisulfite on the nutritional value of full-fat soybeans for chicks. Journal of Animal Science, v.69, p.4477-4486, 1991.

LAWRENCE, T.L.J. Processing and preparation of cereal for pig diets, In: COLE, D.J.A.; HARESIGN, W. (Eds.) Recent developments in the pig nutrition. London: Butterworths, 1985. p.230-45.

MAERTENS, L.; LUZI, E. The effect of extrusion in diets with different starch levels on the performance and digestibility of young rabbits. In: SIMPOSIUM ON HOUSING AND DISEASES OF RABBITS, FURBEARING ANIMALS AND PET ANIMALS, 9., 1995, Celle. Proceedings... Celle: DVG, 1995. p.131-138.

MATTERSON, L.D.; POTTER, L.M.; STUTZ, M.W.; et al. The metabolisable energy of feed ingredients for chickens. Storrs, Connecticut, The University of Connecticut, Agricultural Experiment Station. Research Report, v.7, n.1, p.11-14, 1965.

MENDEZ, J.; RIAL E.; SANTOMÁ, G. Feed Manufacturing. In: DE BLAS, C., WISEMAN, J. (Ed.) The nutrition of the rabbit. Cambridge: CABI Publishing, 1998. p.215-237.
MOREIRA, I. Valor nutritivo e utilização do milho e soja integral processado a calor na alimentação de leitões. Viçosa, MG: Universidade Federal de Viçosa, 1993. 145p. Tese (Doutorado em Zootecnia) - Universidade Federal de Viçosa, 1993.

NOLAND, P.R.; CAMPBELL, D.R.; GAGE, R.K. et al. Evaluation of processed soybeans and grains in diets for young pigs. Journal of Animal Science, v.43, p.763-769, 1976.

ROONEY, L.W.; PFLUGFELDER, R.L. Factor affecting starch digestibility with special emphasis on sorghum and corn. Journal of Animal Science, v.63, p.1607-1623, 1986.

ROSTAGNO, H.S.; ALBINO L.F.T.; DONZELE, J.L. et al. Composição de alimentos e exigências nutricionais de aves e suínos (Tabelas Brasileiras). Viçosa, MG: Universidade Federal de Viçosa, 2000. p.27-34.

SCAPINELLO, C. Níveis de proteína bruta e de energia digestível e exigências de lisina e de metionina + cistina, para coelhos da raça Nova Zelândia Branco em crescimento. Viçosa, MG: Universidade Federal de Viçosa, 1993. 215p. Tese (Doutorado em Zootecnia) - Universidade Federal de Viçosa, 1993.

SCAPINELLO, C.; TAFURI, M.L.; ROSTAGNO, H.S. et al. Valor nutritivo do milho, do farelo de soja e do feno de aveia para coelhos em crescimento.Revista Brasileira de Zootecnia, v.24, n.6, p.1001-1007, 1995.

SILVA, D.J. Análise de alimentos: métodos químicos e biológicos. Viçosa, MG: Universidade Federal de Viçosa, 1990. $166 \mathrm{p}$.

SKOCH, E.R.; BINDER, S.F.; DEYOE, C.W. et al. Effects of steam pelleting conditions and extrusion cooking on a swine diet containing wheat middlings. Journal of Animal Science, v.57, n.9, p.9-35, 1983.

Recebido em: 27/08/02

Aceito em: 10/12/02 